\title{
Corrigendum: Simulated Annealing with Deterministic Decisions
}

\author{
Tasir Eldos \\ Department of Computer Engineering, \\ Jordan University of Science and Technology, Al Ramtha, Irbid Jordan
}

\begin{abstract}
Correction to: Journal of Computer Science http://doi.org/10.3844/jcssp.2009.974.979, published online 01 December 2009; updated 11 April 2018
\end{abstract}

The original version of this Article contained errors in the affiliation for Tasir Eldos.

The correct affiliation for Mr. Tasir Eldos is as follows:

Department of Computer Engineering,

Jordan University of Science and Technology, Al Ramtha, Irbid Jordan

These errors have now been corrected in the HTML and PDF versions of the Article.

http://doi.org/10.3844/jcssp.2018.435 